\title{
Rupture behavior of the 1999 Chi-Chi, Taiwan, earthquake - slips on a curved fault in response to the regional plate convergence
}

\author{
Kuo-Fong $\mathrm{Ma}^{\mathrm{a}, *}$, Ling-Yun Chiao ${ }^{\mathrm{b}}$ \\ ${ }^{a}$ Institute of Geophysics, National Central University, Taiwan, ROC \\ ${ }^{\mathrm{b}}$ Institute of Oceanography, National Taiwan University, Taiwan, ROC
}

\begin{abstract}
Simple kinematic modeling of particle motion along a curved fault similar to the ruptured Chelungpu fault, Taiwan, indicates a unique spatial slip pattern. Specifically, we find that the large convergent slip on the curve is a result of the minimum deformation scenario of the fault geometry and regional northwestern movement of the Philippine Sea Plate (PSP). The modeled deformation regime portrays an accumulation of deformation in the curved region, which coincides very well with a long-term observed NW-SE-trending seismogenic zone in the central Taiwan. This consistence suggests that the Chelungpu fault is a preexisting curved fault. This is further evidenced by geological and geophysical observations. Because the spatial slip pattern is locally and regionally tectonically controlled, it indicates that the rupture behavior of the Chi-Chi earthquake is repeatable. Better knowledge of the fault geometry and the regional plate motion may help us to predict the possible spatial slip distribution of large earthquakes. This discovery is important for avoiding large buildings and constructions near predicted large slip regions.
\end{abstract}

(C) 2003 Elsevier Science B.V. All rights reserved.

Keywords: Chi-Chi, Taiwan, earthquake; Chelungpu fault; Regional plate convergence

\section{Introduction}

The September 20, 1999 Chi-Chi, Taiwan, earthquake $(\mathrm{Mw}=7.6)$ ruptured about $100 \mathrm{~km}$ of the Chelungpu fault with complicated surface faulting (Ma et al., 1999). The ruptured Chelungpu fault system consists of three distinct fault segments with the main segment striking $\mathrm{N} 3{ }^{\circ} \mathrm{E}$, a small segment striking $\mathrm{S} 45^{\circ} \mathrm{W}$ at the south and a northern segment striking $\mathrm{N} 80^{\circ} \mathrm{E}$ that splinters into more complicated

\footnotetext{
* Corresponding author. Institute of Geophysics, National Central University, Taiwan, ROC.

E-mail address: fong@rupture.gep.ncu.edu.tw (K.-F. Ma).
}

traces. The largest dislocation (up to $8 \mathrm{~m}$ ) and faultslip velocity (up to $3 \mathrm{~m} / \mathrm{s}$, Shin et al., 2000) were observed near the region where the fault bends to the northeast. Within a few hundred meters of the fault, severe damage is usually associated with ground deformation of the hanging wall rather than with strong shaking.

Well-recorded strong motion waveforms and GPS data have provided important information on deciphering the nature of the fault behavior. There have been several studies on the earthquake rupture process (Ma et al., 2001; Zeng and Chen, 2001; Wu et al., 2001; Chi et al., 2001; Ji et al., submitted for publication). Regardless of the differences of the method and data employed, the results consistently show large 
slips of up to $10-15 \mathrm{~m}$ at the northern end and the bent northeastern extension of the fault. The spatial pattern of slip distribution reveals a rotation of the slip angle during fault rupture. Considering surface rupture of the Chelungpu fault, the spatial slip distribution derived from Ji et al. (2003) also indicates a significant fault rupture where the fault bends to the northeast (Fig. 1).

The rupture behavior as revealed from strong motion waveform inversion studies yields a question of what is the mechanism of generating the large slip and slip velocity observed at stations TCU068 and
TCU052 located near the northern bending region? Why did the fault bend to the northeast as it ruptured? Is the bent fault a preexisting geological feature that controls the rupture process or, rather, did the earthquake rupture create a new curved surface trace? Despite the distributed slip rotation along the rupture surface, the average slip direction on the surface is, in general, consistent with the direction of the regional plate convergence between the Eurasia Plate (EP) and the Philippine Sea Plate (PSP) (Seno et al., 1993; Fig. 1). As Taiwan is situated on the plate boundary, it is clear that the occurrence of the 1999 Chi-Chi
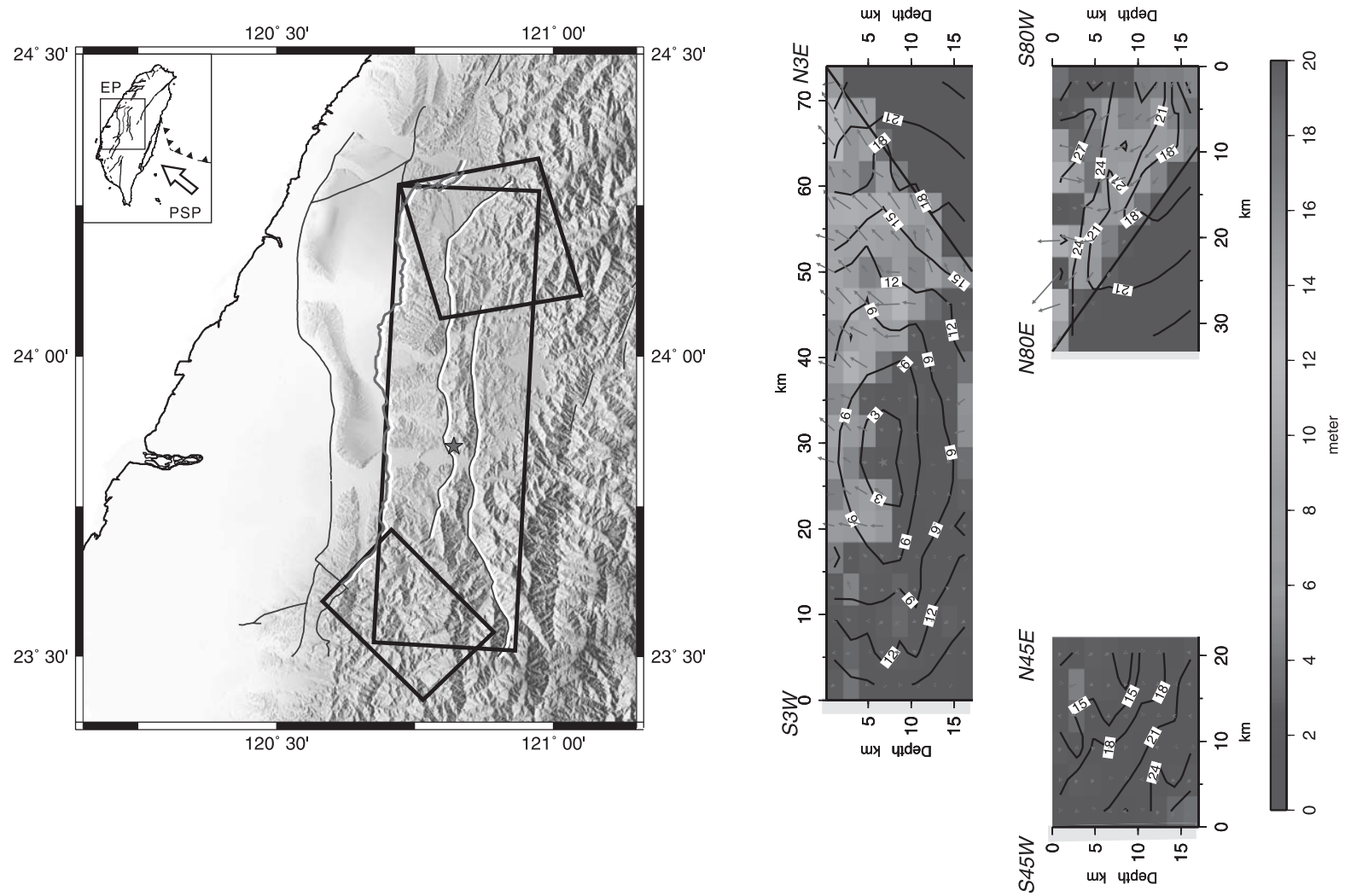

Fig. 1. Fault geometries, active fault distributions, and tectonic setting of Taiwan. The map is shown together with 25-m-resolution DTM morphology data. The geometry of the Chelungpu fault is separated into three segments, SW, NS, and NE shown by black boxes. The red line represents the ruptured Chelungpu fault during the Chi-Chi earthquake. The blue lines represent the identified active faults from the Central Geological Survey of Taiwan. The tectonic setting is inserted in the box. The arrow indicates the NW movement of the Philippine Sea Plate (PSP) to the Eurasian Plate (EP) with a velocity of about $8 \mathrm{~cm} /$ year. The detail slip distribution on the Chelungpu fault plane is from Ji et al. (2003). The yellow bold lines indicate the corresponding sides of the slip distribution on the three faults to the fault segments projected in the map. Slip magnitude is color-coded, whereas slip directions are shown by arrows. The contours indicate the rupture initiation time at 3-s intervals. A red star displays the location of the hypocenter, and the black line indicates the intersection of NS and NE fault segments. 
earthquake is caused tectonically by the relative plate convergence. In this study, we devise a simple kinematic model to study the particle motion along the curved fault surface. We fix the western side of the fault (the footwall) and let the far field kinematics of the eastern side (the hanging wall) be compatible with the relative plate convergence between the PSP and the EP. We then analyze the kinematics along the fault surface as well as the corresponding in-plane deformation, which represents the deformation associated with the spatial slip pattern along the fault surface. The result seems to be consistent with various geological and geophysical observations. We thus propose that the spatial rupture behavior of the earthquake could be related to the minimum deformation scenario along a preexisting nonplanar fault constrained by the local plate tectonics.

In addition to the consistency of the kinematic model to the spatial slip distribution, we also show that the stress accumulation near the bend in the model might be responsible for the northwest-southeast seismogenic zone observed in central Taiwan, suggesting that the NW-SE seismogenic zone is a result of the interaction of the fault geometry with local tectonics. It implies that the northeast bend of the ruptured fault is a preexistence feature. This is also evidenced by other geological and geophysical observations. If the earthquake rupture is indeed the result of the response of a preexisting nonplanar fault to local tectonics, the spatial slip pattern over the fault can be predicted through kinematic modeling that reveals large slip near the bend. This information is important for earthquake engineering to reduce construction near the expected large slip region that usually yields longer period of waves.

\subsection{Kinematic modeling of particle motion along the fault surface}

Based on the observation that the average horizontal slip direction along the Chelungpu fault is consistent with the direction of the plate convergence of PSP vs. EP, the general consensus concerning the Chi-Chi earthquake is that it is fundamentally controlled by the local tectonics. The core of plate tectonics describes relative motion between any two plates on the surface of the Earth as rigid body rotation. This is possible because plate tectonics occurs on the nearly perfect Earth's spherical surface on which the rotational Euler's velocity field, free from internal deformation, can be configured. The situation becomes much more complicated when other non-Euclidean backgrounds, with spatially varying curvature, are considered. Creager and Boyd (1991), Chiao (1993), Chiao et al. (2001) as well as Chiao and Creager (2002) considered subduction flow fields occurring along subducted slabs and found that it is, in general, not possible to allow flow fields free from the in-plane deformation due to the geometric configuration of slabs. They define the in-plane deformation as strain-rate components associated with the internal dilatation and shearing within the local tangential plane. Furthermore, they argue that the "principle of the least in-plane deformation rate" governs the general behavior of a geodynamical velocity (or displacement) field along a surface. This principle predicts the familiar Euler's rotation on a spherical surface and leads to flow field minimizing the integrated dissipation power for other non-Euclidean surfaces such as the subducted slab.

If it is adequate to presume a simple planar geometry for describing the Chelungpu fault, then it is very easy to assume a uniformly free-slipping displacement (or velocity) field on the fault plane, which is free from any in-plane deformation, in responding to the northwestern plate convergence. Unfortunately, the drastic bending of the fault surface in the north precludes the definition of such a simple geometry. It is thus interesting to determine the plausible slip pattern on this curved fault surface driven by the far-field general plate convergence with the least amount of in-plane deformation embedded. That is, before other complications, such as the asperity pattern that might be spatially varying, are considered, we wish to examine the direct impact of the geometric effect of the fault surface on the slip kinematics along the fault in this study.

We consider a simplified, nonplanar fault geometry, with a strike of $\mathrm{N} 3{ }^{\circ} \mathrm{E}$ for a segment of $80 \mathrm{~km}$, curving to $\mathrm{N} 80^{\circ} \mathrm{E}$ in the north end and extending for $20 \mathrm{~km}$. The dip angle is set to be $30^{\circ} \mathrm{E}$ along the entire fault. The far-field PSP-EP plate convergence, as the boundary condition, is set to a speed of $8 \mathrm{~cm} /$ year at the direction of $\mathrm{N} 45^{\circ} \mathrm{W}$. In all the following calculations, we assume that the footwall (EP side) is fixed and that the velocity vector field along the fault 
surface of the hanging wall (PSP side) relative to the footwall and the local geometry of the fault surface is parameterized by cubic variations within triangular $C_{1}$ elements. This is analogous to the discretization invoked in the Finite Element Method. Based on different considerations, we perform the following three different modeling experiments. In the first experiment, we perform a direct forward calculation assuming that the particle motion along the fault, simulating the slips along the fault surface, can be obtained by directly rotating the plate convergence vector onto the local tangential plane of the fault surface. The deformation rate calculated by taking the symmetric part of the spatial gradient of the velocity field reveals significant in-plane deformation. The second and third experiments are inversions seeking for the optimal velocity field and the geometric configuration that leads to the least amount of the integrated deformation rate for two different boundary conditions. We show that for the Chelungpu fault geometry, constrained by various geological and geophysical observations, it is simply impossible to configure a slip field free from in-plane deformation. In fact, several important kinematic characteristics along the Chelungpu fault might be attributed to the impact of the tight curvature imposed by the drastic northern bend.

\subsubsection{In-plane kinematics obtained by simple rotation}

Following the conventional wisdom of plate tectonics, the extreme scenario of plate kinematics on the surface of the Earth should be close to the rigid body rotation. Based on this, the simplest way of constructing particle kinematics along the fault surface is to rotate the plate convergence vectors onto the fault surface (Fig. 2a). We calculate the in-plane
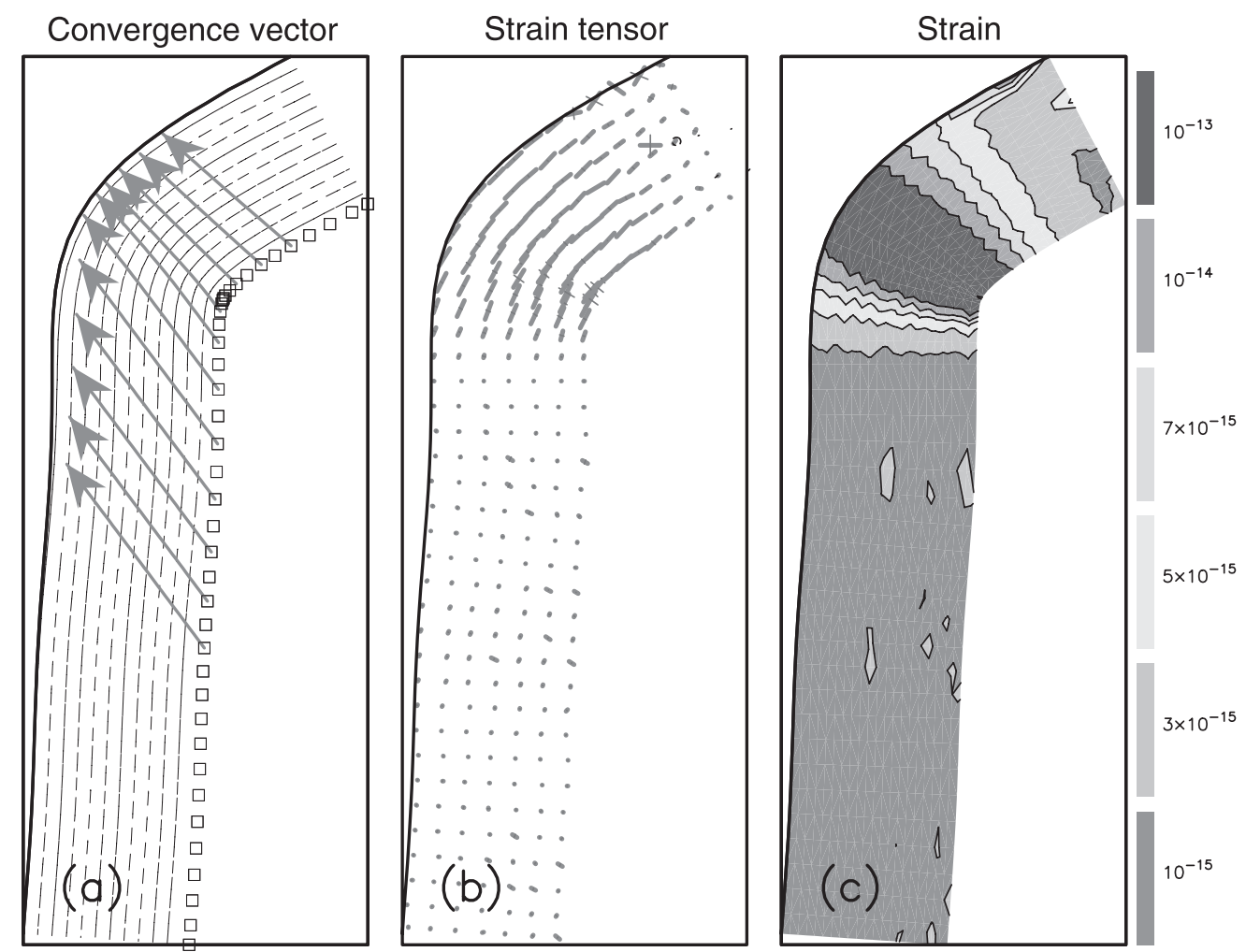

Fig. 2. (a) The velocity vectors on the fault surface simulating the in-plane kinematics that are obtained by direct rotation of the plate convergence vector field are marked by arrows. The dashed lines indicate the depth contours that depict the prescribed geometry of the fault surface. (b) Principle axes of the in-plane deformation tensor. Bold and thin bars indicate the compressional and extensional deformation respectively. (c) Color-coded magnitude of the amount of the effective strain rates. 
deformation rate tensor $\mathbf{D}^{\mathrm{pp}}$ for this particular kinematic field by

$\mathbf{D}^{\mathrm{pp}}=\mathbf{P} \cdot \mathbf{D} \cdot \mathbf{P}^{T}$,

where $\mathbf{D}$ is the strain-rate tensor calculated by taking the symmetric part of the spatial gradient of the velocity vector field; $\mathbf{P}=\mathbf{I}-\mathbf{e}_{\mathrm{n}} \mathbf{e}_{\mathrm{n}}^{T}$ is the projection operator with $\hat{e}_{\mathrm{n}}$ being the local unit normal vector perpendicular to the curved fault surface, $\mathbf{e}_{\mathrm{n}} \mathbf{e}_{\mathrm{n}}^{T}$ being the dyadic outer product, and I being the identity operator. Principle axes of the in-plane deformation tensor thus obtained reveal considerable along-strike contraction accumulated around the bending region (Fig. 2b). Furthermore, the effective strain rate is calculated by taking the square root of one half of the in-plane strain-rate tensor contracted with itself,

$\dot{\varepsilon}^{\mathrm{ef}}=\sqrt{\left(\mathbf{D}^{\mathrm{pp}}: \mathbf{D}^{\mathrm{pp}}\right) / 2}$.

Contours of the magnitude of the effective strain rates (Eq. (2)) imply the same concentration around the bending region (Fig. 2c).

\subsubsection{Minimization of the in-plane deformation}

The simple kinematics constructed by rotating the plate convergence field yields considerable deformation along the fault surface (Fig. 2), which contradicts the original intention of following the plate kinematics directly. An alternative scheme is to construct the velocity field along the given fault geometry based on the rationale that the in-plane deformation should be minimized (Chiao et al., 2001). That is, for the given curved fault geometry away from the bending, we calculate both the velocity field on the fault surface that is consistent with the plate convergence in the far field as well as the optimized fault geometry around the bend that yields the minimum in-plane deformation. The result reveals that the in-plane deformation is relaxed considerably (compare Fig. $3 \mathrm{c}$ with Fig. 2c). Notice that the optimized fault geometry, which yields much reduced in-plane deformation, is characterized by a significantly shallower dipping angle around the bend (Fig. 3a). Furthermore, considerable undulation of the hanging wall is indi-

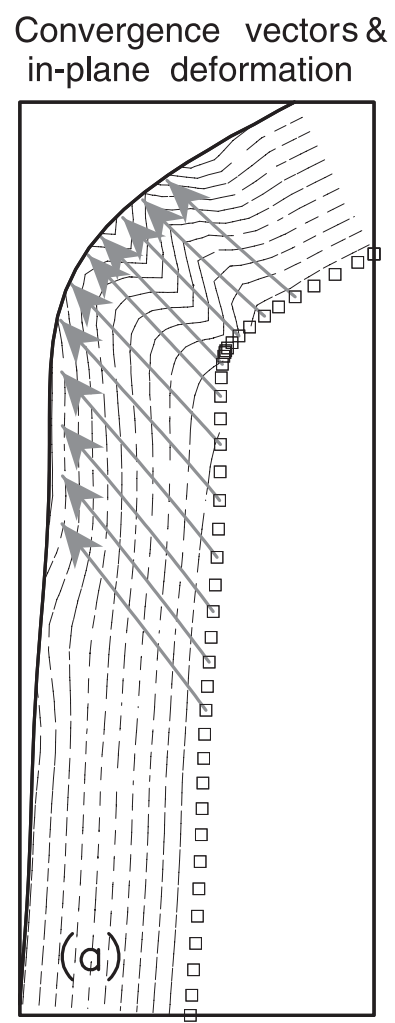

\section{Strain tensor}

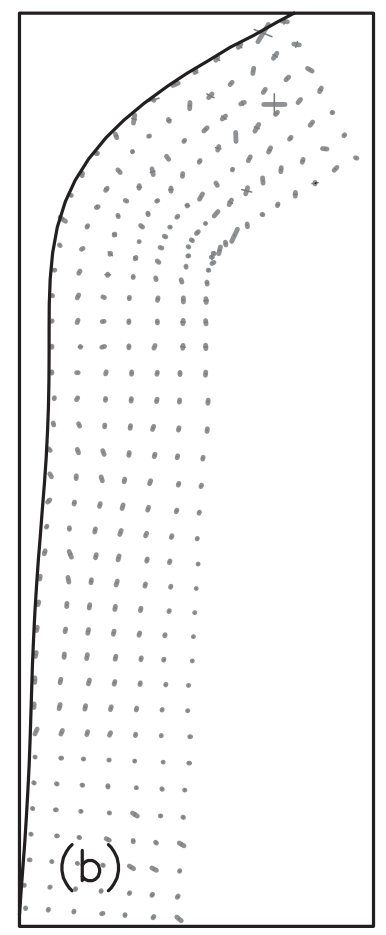

Strain

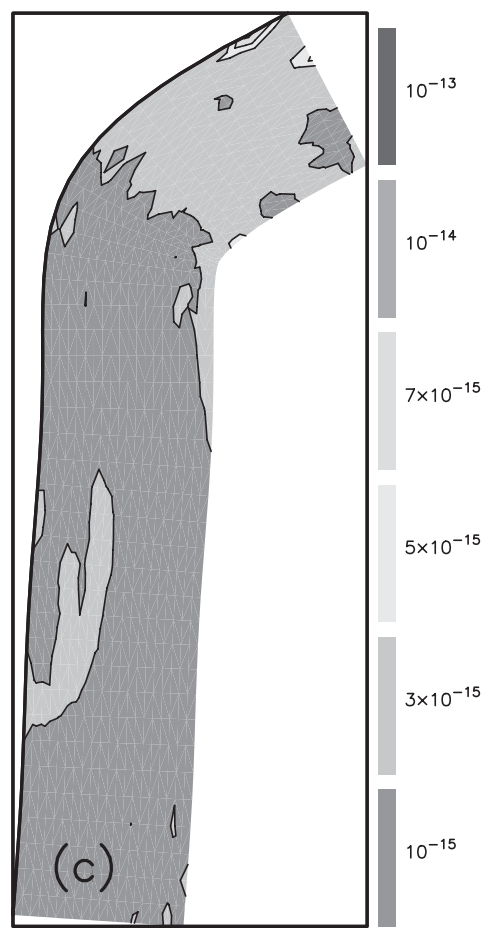

Fig. 3. Same as Fig. 2, except that the in-plane kinematics as well as the fault geometry are tuned to minimize the in-plane deformation. 
cated along the surface trace of the fault in the bend axis.

\subsubsection{Minimize the in-plane deformation without surface break}

To avoid the undulation along the surface trace of the fault around the bend axis, another geometric boundary condition is imposed such that the shallowest dip close to the surface around the bend is not perturbed when minimizing the in-plane deformation. Consequently, the unrealistic surface undulation is quelled (Fig. 4a). However, the flattening of the dip angle toward the bend is still significant. The in-plane deformation along the rupture surface (Fig. 4c) is higher than the previous experiment (Fig. 3c), but is still significantly reduced as compared to the rigid motion scenario (Fig. 2c). Higher in-plane deforma- tion is clearly concentrated at the shallow depths around the bend.

These three calculations might be interpreted as representing different status of the in-plane deformation along the nonplanar fault geometry as responding to constraints from the local plate convergence. In summary, if the faulting took place as a consequence of the strictly rigid body convergence between the two plates (the first experiment), very high in-plane deformation will accumulate in the bend region with noticeable slip convergence toward the bend axis. To reduce the accumulated deformation, the particle motion along the fault surface and the fault geometry around the bend are adjusted. This leads to undulation of the hanging wall around the bend (the second experiment). Imposing additional geometric boundary condition along the surface trace removes the undu-

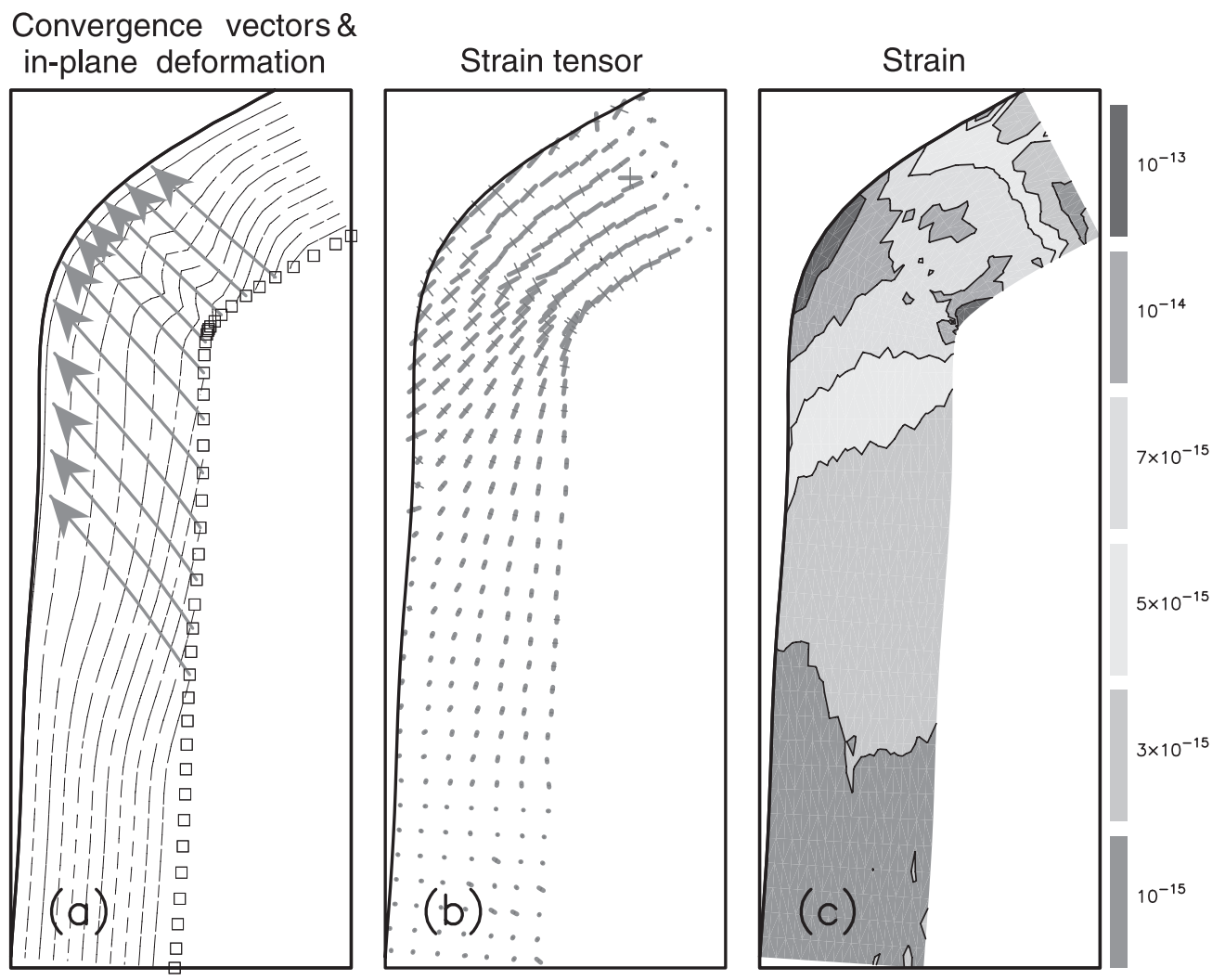

Fig. 4. Same as Fig. 3, except that an additional boundary condition on the fault geometry is imposed such that the shallowest dip angle close to the surface is not allowed to be modified during the minimization that leads to the optimal velocity field and the surface geometry. This is to quell the unrealistic, wild uplifting of the hanging wall near the northern bend (Fig. 2a). 
lation and yields concentration of the in-plane deformation in the shallow depths near the bend, while the fault plane flatten toward the bend axis (the third experiment).

Comparing the results from the three kinematic models to the rupture of Chelungpu fault, Case (1) could be representative of the fault status before the occurrence of the Chi-Chi earthquake. The deformation accumulated in the bend region as revealed in the background seismicity. The scenario portrayed by Case (2) and Case (3) appears to reflect certain aspects of the kinematic fault behavior during the fault rupture as the earthquake occurred. Slips converge near the bend while seeking for an optimized rupture surface (flattening toward the bend axis) to relax the accumulated deformation. This slip behavior is consistent with the observed spatial slip distribution (Fig. 1a). The flattening of the dip angle toward the north is also consistent with observations from the seismic reflection experiment (Wang et al., 2002). Lee et al. (in press) studied the geometry and structure of northern ruptures of the Chi-Chi earthquake. They suggest that the Chelungpu fault ruptured along the bedding plane of the Chinshui Shale, which tends to be shallower at the northern end of the fault. The development of the earthquake rupture might thus be influenced by bedding parallel slip following a lower deformation configuration.

\subsection{Kinematic model and seismicity}

Wang and Shin (1998) reviewed 100 years of Taiwan seismicity. Most of the seismicity is highly correlated to the tectonic setting of Taiwan as related to the subduction of the PSP to the northeast and the subduction of EP to the south. The seismicity inland is related to active faults, especially in southwestern Taiwan. Due to the highly developed thrust fault system in the arc-continent collision regime of Taiwan, the seismicity is sometimes not directly related to specific active faults, but is, in general, bounded by the fault system surrounding them. They revealed a significant NW-SE-trending seismogenic zone in central Taiwan. Fig. 5 shows 10 years of seismicity in the northwestern Taiwan near the Chi-Chi earthquake rupture region. There is an obvious lack of seismicity in the Chi-Chi earthquake rupture area prior to the earthquake. Furthermore, a distinct seismogenic zone as identified by Wang and Shin (1998) trending from northwest to southeast coincides very well with the bending axis of the ruptured Chelungpu fault. The lack of seismicity in the Chi-Chi rupture area indicates that the Chelungpu fault was locked before the earthquake rupture. The coincidence of the NW-SE seismogenic zone to the bend of the fault (Fig. 5a) indicates possible stress accumulation near the bend. From geomorphic data, Deffontaines et al. (1994) observed transfer fault zones, which might be associated with the NW-SE seismogenic zone, within the central Taiwan.

As kinematic models discussed in the previous section show strain accumulation around the bend axis due to the interaction of the curved fault to the NW movement of the plate, we compare the strain field with the background seismicity as shown in Fig. 5b. Although the kinematic model is calculated under rather simplified assumptions, the NW-SEtrending seismogenic zone coincides very well with the spatial strain accumulation in the bend. This coincidence seems to indicate that the NW-SEtrending seismogenic zone might be related to deformation accumulation due to the interaction of the curved fault geometry and the local plate convergence. The correlation of the NW-SE seismogenic zone existed prior to the Chi-Chi earthquake with the calculated strain-rate pattern also suggests the existence of the preexisting curved fault of the Chelungpu fault. The interaction of the curved fault and NW movement of PSP results in a significant large amount of slip near the surface around the bend and the convergence of slip directions toward the bend axis as observed. That is, the kinematics of the rupture behavior of the Chi-Chi earthquake is locally and regionally tectonically controlled.

\subsection{Evidence on preexisting curved fault}

The identified Changhua and Shangtung active faults distribution (Fig. 5a) in Central Taiwan both bend to the northeast. However, the Chelungpu fault was not identified as a curved fault in the geology map of Central Geological Survey of Taiwan priori to the earthquake, shown by thin straight line in the northern portion of the fault. The ruptured curved Chelungpu fault shown in the bold line forms a trend consistent with the fault system nearby. This interest- 
ing geological feature seems to imply that the bending of the Chelungpu fault should not be a surprise.

If the Chelungpu fault is a preexisting curved fault and the rupture is tectonically controlled, we would expect similar spatial slip patterns along the Chelungpu fault from prehistorical events, if there are any. One way to check this is to seek geological evidence near the bend, especially on the hanging wall. Chen et al. (2002) investigated thrust-related river terrace development in the northern portion of the Chelungpu fault. Along the Tachia River, where the fault bends to the northeast, they observed eight well-developed terrace levels in the hanging wall. The bottom five levels were lateritic, while the top three levels are nonlaterisic. The footwall has five corresponding lateritic terrace levels. No nonlaterized terrace levels were found in the footwall. Additionally, the five lateritic terrace levels in the hanging wall had been uplifted by $50 \mathrm{~m}$ compared to that in the footwall. This observation suggests that the hanging wall near the Tachia River has been significantly uplifted several times. Trench studies near the bend, (Chen et al., 2003, 2002) and Lee et al. (2002b) reveal that the basement on the hanging wall is rather shallow, indicating that the fault had been substantially uplifted. Several possible paleoevents were identified,

(a)

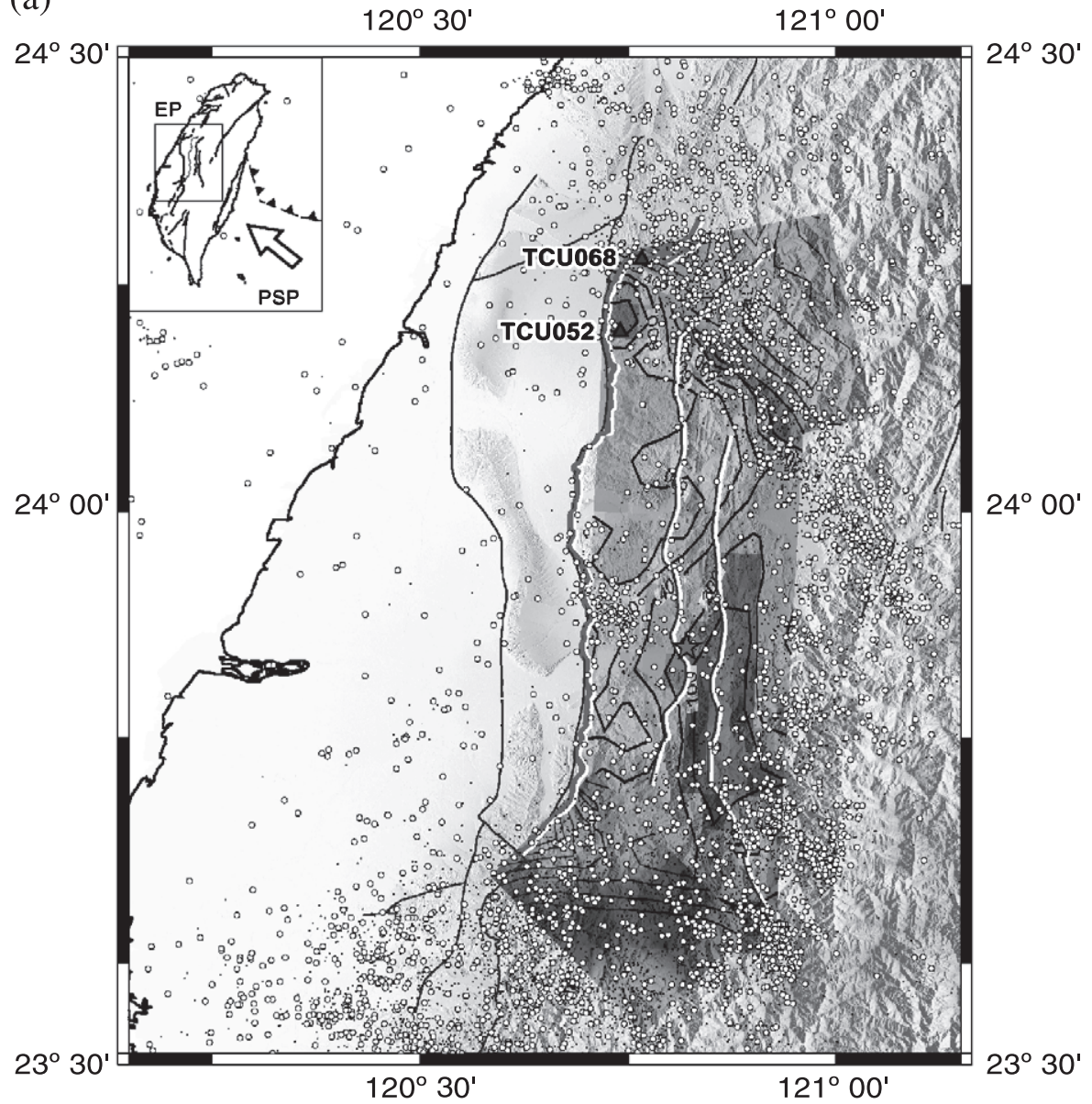

Fig. 5. The seismicity (dots) 10 years before the 1999 Chi-Chi earthquake with (a) spatial slip distribution of Fig. 1, and (b) strain distribution of Fig. 4c. The main active faults in the map from the left to the right are Changhua, Chelungpu, Shantung, and Chuchih faults. The stations TCU068 and TCU052 are shown by triangles. Other symbols represented in this figure are the same as those in Fig. 1. 
(b)

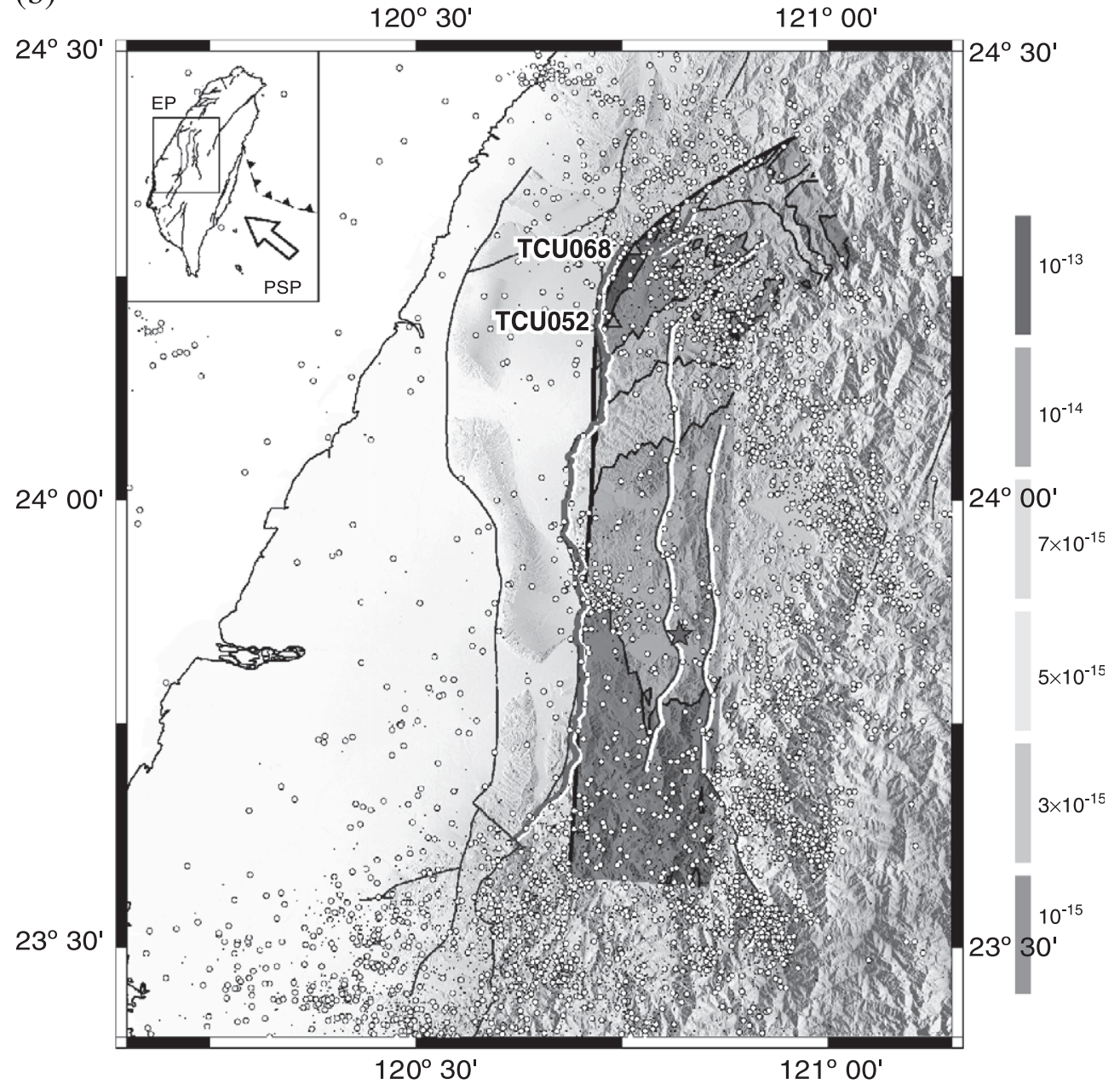

Fig. 5 (continued).

but no detail dating information is yet available. As mentioned earlier, Lee et al. (2002a) investigated the geometry and structure of the northern surface rupture of the Chi-Chi earthquake. They also concluded that the Chi-Chi earthquake ruptured on a preexisting bending fault along a weak bedding plane in the Pliocene Chinshui Shale, which tends to be shallower to the north consistent with the kinematic model shown in Fig. 3a. This suggests again that the Chi-Chi earthquake ruptured a preexisting nonplanar fault, and the spatial slip pattern on the curved fault is a response to regional plate convergence.

\section{Discussion}

In the kinematic calculations of particle motion on the particular fault geometry, we show that the pattern of spatial slip distribution and convergence of large slips in the bend region can be explained by the interaction between the preexisting nonplanar fault and the plate convergence. The kinematics of the slip behavior and the in-plane deformation predicted by the simulation are consistent with geological characteristics (Lee et al., 2002a) and other observations revealed from shallow reflection experiments (Wang et al., 2002). The existence of a NW-SE seismogenic 
zone in this area that is speculated to be related to the deformation accumulated in the bend implies the preexisting curved fault. This is further supported in the geomorphology and paleoseismology study.

Although we still do not understand why and how the earthquake was initiated at Chi-Chi, we believe that the overall general characteristics of the slip pattern is kinematically controlled by the interaction of the curved fault and the northwestern plate convergence of PSP vs. EP. An interesting feature of this earthquake is the large slip and slip velocities, but lower acceleration with low amount of high-frequency acceleration, observed at seismograph stations TCU052 and TCU068 located near the northern bend of the fault (Fig. 5a). Ma et al. (2003) proposed an explanation relating the observed abnormal large slip velocities and less amount of high frequency acceleration observed at these two stations to a fault lubrication model. They suggested that as the displacement exceeds a threshold, lubrication pressure becomes high enough to widen the fault gap, thereby reducing the area of asperity contact. This suppresses high-frequency ground motion while maintaining large velocity and displacement. Lubrication during the fault rupture is a dynamic behavior depending upon when and where significant slips exceed the threshold. In this study, we proposed that the interaction of the local nonplanar curved fault and NW plate motion of the PSP will concentrate stress resulting in sudden large slips that exceed the threshold for fault lubrication.

If the spatial pattern of the slip distribution is indeed controlled by the fault geometry and the local plate convergence, we suspect that rupture behavior similar to the Chi-Chi earthquake will take place again as is also supported by prehistoric events from trenching. Although the recurrence time is hard to estimate, Andrews et al. (2001) and Ma and Andrews (2002) calculated stress drop over the fault plane and suggested that there is a total release of stress at shallow depths $(30-50 \mathrm{MPa})$ at the northern main fault segment. Thus, the recurrence time might be the time needed to accumulate $30-50 \mathrm{MPa}$ of stress near the surface of the fault. Another point worth mentioning is that field observations reveal less slip in the southern segment of the fault, as is also indicated in our kinematic simulation. The consistence between observations and kinematic simulation simply implies that it is not necessary to have several smaller events at the southern portion of the fault to compensate the large slips at the north. Our study suggests that further knowledge of the fault behavior within the framework of the tectonic setting is thus very important for the earthquake hazard mitigation, as the spatial slip pattern can be predictable kinematically.

\section{Conclusion}

The kinematic simulation of the Chi-Chi earthquake along with the background seismicity and other geological evidences suggest that the Chi-Chi earthquake ruptured on a preexisting fault. The spatial slip distribution pattern is a result of the interaction of the preexisting nonplanar fault and the northwestern convergence of PSP. The interaction might generate large slips in the northern section of the fault and helps to exceed the fault lubrication threshold proposed by Ma et al. (2003). The kinematic simulation also suggests that further knowledge of the fault geometry and the regional plate motion may help to predict the possible spatial slip distribution of large earthquakes. This discovery is important for engineering of avoiding large buildings and construction near predicted large slip regions, which generate longer period waves.

\section{References}

Chen, W.-S., Chen,Y.-G., Shih, R.-C., Liu, T.-K., Huang, N.-W., Lin, C.-C., Sung, S.-H., Lee, K.-J., 2002. Thrust-related river terrance development in relation to the 1999 Chi-Chi earthquake rupture, Western Foothills, central Taiwan, 21, 473-480.

Chen, W.-S., Lee, K.-J., Lee ${ }^{\mathrm{a}}$, L.S., Ponti, D.J., Prentice, C., Chen, Y.e-G., Chang, H.-C., Lee, Y.-H., 2003. Paleoseismology of the Chelungpu Fault During the Past 1900 Years, Quaternary International [accepted].

Chi, W.-C., Dreger, D., Kaverina, A., 2001. Finite-source modeling of the 1999 Taiwan (Chi-Chi) earthquake derived from a dense strong-motion network. Bull. Seismo. Soc. Am. 91, $1144-1157$.

Chiao, L.-Y., 1993. Strain segmentation and lateral membrane deformation rate of the subducted Ryukyu slab. Isl. Arc 2, 94-103.

Chiao, L.-Y., Creager, K.C., 2002. Geometry and the membrane deformation rate of the subducting Cascadia slab. In: Kirby, S., Wang, K., Dunlop, S. (Eds.), The Cascadia Subduction Zone and Related Subduction Systems - Seismic Structure, Intraslab Earthquakes and Processes, and Earthquake Hazards. U.S. Geo- 
logical Survey Open-File Report 02-328, and Geological Survey of Canada Open File 4350. 169 pp.

Chiao, L.-Y., Kao, H., Lallemand, S., Liu, C.-S., 2001. An alternative interpretation for slip vector residuals of subduction interface earthquakes: a case study in the westernmost Ryukyu slab. Tectonophysics 333, 123-134.

Creager, K.C., Boyd, T.M., 1991. The geometry of Aleutian subduction: three-dimensional kinematic flow modeling. J. Geophys. Res. 96, 2293-2307.

Deffontaines, B., Lee, J.-C., Angelier, J., Carvalho, J., Rudant, J.-P., 1994. New geomorphic data on the active Taiwan orogen: a multisource approach. J. Geophys. Res. 99, 20243-20266.

Ji, C., Helmberger, D.V., Wald, D.J., Ma, K.-F., 2003. Slip history and dynamic implications of 1999 Chi-Chi, Taiwan earthquake. J. Geophys. Res. (in press).

Lee, J.-C., Chu, H.-T., Angelier, J., Chan, Y.-C., Hu, J.-C., Lu, C.Y., Rau, R.-J., 2002a. Geometry and structure of northern surface rupture of the $1999 \mathrm{Mw}=7.6 \mathrm{Chi}-\mathrm{Chi}$, Taiwan earthquake: influence from inherited fold belt structures. J. Struct. Geol. 24, $173-192$.

Lee, Y.-H., Wu, W.-Y., Shih, T.-S., Lu, S.-D., Hsieh, M.-L., 2002b. The deformation mechanism of the surface ruptures at the northern end of the Chi-Chi earthquake, $\mathrm{Mw}=7.6$, Central Taiwan. Bull. Seismol. Soc. Am. (submitted for publication).

Ma, K.F., Andrews, J., 2002. Dynamic parameters determination of the 1999 Chi-Chi Taiwan earthquake. EOS, Trans. 83 (47) (AGU).

Ma, K.F., Lee, C.-T., Tsai, Y.-B., Shin, T.-C., Mori, J., 1999. The
Chi-Chi, Taiwan earthquake: large surface displacements on an inland thrust fault. EOS, Trans. 80, 605.

Ma, K.F., Mori, J., Lee, S.J., Yu, S.B., 2001. Spatial and temporal distribution of slip for the 1999 Chi-Chi, Taiwan, earthquake. Bull. Seismol. Soc. Am. 91, 1069-1087.

Ma, K.F., Brodsky, E.E., Mori, J., Ji, C., Song, T.R.A., Kanamori, H., 2003. Evidence for fault lubrication during the 1999 Chi-Chi, Taiwan, earthquake (Mw7.6). Geophys. Res. Lett. 30 (5), 1244 (doi: 10.1029/2002GL015380).

Seno, T., Stein, S., Gripp, A.E., 1993. A model for the motion of the Philippine Sea Plate consistent with NUVEL-1 and geological data. J. Geophys. Res. 98, 17941-17948.

Shin, T.C., Kuo, K.W., Lee, W.H.K., Teng, T.L., Tsai, Y.B., 2000. A preliminary report on the 1999 Chi-Chi (Taiwan) earthquake. Seismol. Res. Lett. 71, 24-30.

Wang, C.Y., Shin, T.-C., 1998. Illustrating 100 years of Taiwan seismicity. TAO 9, 589-614.

Wang, C.Y., Li, C.L., Yen, H.Y., 2002. Mapping the northern portion of the Chelungpu fault, Taiwan, by shallow reflection seismic. Geophys. Res. Lett. 29, 951-954.

Wu, C., Takeo, M., Ide, S., 2001. Source process of the Chi-Chi earthquake: a joint inversion of strong motion data and global positioning system data with multifault model. Bull. Seismol. Soc. Am. 91, 1128-1143.

Zeng, Y., Chen, C.-H., 2001. Fault rupture process of the 20 September 1999 Chi-Chi, Taiwan, earthquake. Bull. Seismol. Soc. Am. 91, 1088-1098. 